\title{
Assessment of evaluations made to healthy eating policies in Europe: a review within the EATWELL Project
}

Federico JA Pérez-Cueto ${ }^{1, *}$, Jessica Aschemann-Witzel ${ }^{2}$, Bhavani Shankar ${ }^{3,8}$, José Brambila-Macias $^{3}$, Tino Bech-Larsen ${ }^{2}$, Mario Mazzocchi ${ }^{4}$, Sara Capacci ${ }^{4}$, Anna Saba ${ }^{5}$, Aida Turrini ${ }^{5}$, Barbara Niedzwiedzka ${ }^{6}, B$ Beata Piorecka ${ }^{6}$, Agniezska Kozioł-Kozakowska ${ }^{6}$, Josephine Wills ${ }^{7}$, W Bruce Traill ${ }^{3}$ and Wim Verbeke ${ }^{1}$

'Department of Agricultural Economics, Ghent University, Coupure Links 653, B-9000 Ghent, Belgium: ${ }^{2}$ Centre for Research on Customer Relations in the Food Sector, Aarhus School of Business, Aarhus University, Aarhus, Denmark: ${ }^{3}$ Department of Agricultural and Food Economics, University of Reading, Reading, UK: ${ }^{4}$ Department of Statistics, Alma Mater Studiorum-Universita Di Bologna, Bologna, Italy: ${ }^{5}$ Istituto Nazionale di ricerca per gli Alimenti e la Nutrizione, Rome, Italy: Institute of Public Health, The Jagiellonian University Medical College, Cracow, Poland: ${ }^{7}$ European Food Information Council asbl, Brussels, Belgium: ${ }^{8}$ Leverhulme Centre for Integrative Research on Agriculture and Health, and School of Oriental and African Studies, University of London, London, UK

Submitted 11 March 2011: Accepted 27 October 2011: First published online 29 November 2011

\begin{abstract}
Objective: To identify and assess healthy eating policies at national level which have been evaluated in terms of their impact on awareness of healthy eating, food consumption, health outcome or cost/benefit.

Design: Review of policy documents and their evaluations when available.

Setting: European Member States.

Subjects: One hundred and twenty-one policy documents revised, 107 retained. Results: Of the 107 selected interventions, twenty-two had been evaluated for their impact on awareness or knowledge and twenty-seven for their impact on consumption. Furthermore sixteen interventions provided an evaluation of health impact, while three actions specifically measured any cost/benefit ratio. The indicators used in these evaluations were in most cases not comparable. Evaluation was more often found for public information campaigns, regulation of meals at schools/canteens and nutrition education programmes.

Conclusions: The study highlights the need not only to develop harmonized and verifiable procedures but also indicators for measuring effectiveness and success and for comparing between interventions and countries. EU policies are recommended to provide a set of indicators that may be measured consistently and regularly in all countries. Furthermore, public information campaigns should be accompanied by other interventions, as evaluations may show an impact on awareness and intention, but rarely on consumption patterns and health outcome.
\end{abstract}

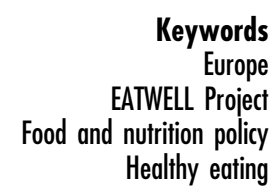

Europe nutrition policy Healthy eating
The sustained increase in overweight and obesity prevalence in Europe observed during the past two decades has become a serious public health concern ${ }^{(1-4)}$, demanding the direct involvement of governments of the European Union (EU) Member States ${ }^{(3,5)}$. The associations between diet and health are not solely through overweight and obesity, but are mediated through overall diet and lifestyle $^{(6)}$. The Food Standards Agency in the UK has calculated that 42000 lives could be saved by increasing fruit and vegetable consumption to the five-a-day target (from about 3.5 portions) and 20000 lives by reducing salt intake (from 9 to $6 \mathrm{~g} / \mathrm{d})^{(7)}$. In the USA, $1 \%$ individual weight loss could result in an annual saving of \$US 213 per diabetes patient ${ }^{(8)}$. The fiscal effects of smoking, and in particular obesity, are large enough to become part of the social welfare calculation for evaluating changes in these two health behaviours and improvements in life expectancy ${ }^{(9)}$.

Responding to the endorsement of the WHO European Region's First Action Plan for Food and Nutrition Policy, fifty-one member states started implementing Action Plans at national level. A majority (75\%) of WHO European Member States had developed national food and nutrition policies by $1998 / 1999$, but they were still lacking the national structures for the implementation. Most WHO European Member States had developed references for nutrient intakes and healthy eating guidelines. Furthermore, main nutrition-related outcomes were identified (chronic noncommunicable diseases, obesity, iron-deficiency anaemia, 
iodine deficiency disorder), resulting in a call for policies that would aim at enhancing health, living conditions and equality for the European population ${ }^{(10)}$. Such considerations were the basis for the WHO Regional Office for Europe's request to implement concerted actions in different countries to tackle the challenge of obesity through healthy eating and increased physical activity ${ }^{(3)}$ and to launch the Second Action Plan for Food and Nutrition Policy 2007-2012, which specifically states that 'Incorporation of monitoring and evaluation in every policy or programme contributes to the establishment of evidence-based public health' ${ }^{,(11)}$. Many EU Member States have drafted policy papers in response to it, but large variations are observed between them in terms of terminology, nutritional recommendations, institutional framework, nutritional scope, social groups targeted, and monitoring and evaluation structures $^{(12)}$. Such actions and policies include the concept of healthy eating, its promotion and advice for intake levels. However, most policies have not been evaluated formally, and where they have, recommendations remain suggestive $^{(13-16)}$. Against this background, the EU Seventh Framework Programme collaborative research project EATWELL (Interventions to Promote Healthy Eating Habits: Evaluation and Recommendations) responds to the perceived need to provide accurate information as a basis for the efficient design of future policies ${ }^{(17,18)}$. The objective of the present paper is to identify and assess healthy eating policies at national level that have been evaluated in terms of their impact on awareness of healthy eating, food consumption, health outcome or cost/benefit. Furthermore, the paper highlights which kind of policies 'worked' and which ones did not.

\section{Methodology}

Healthy eating policies were defined as 'any government action which can affect people's healthy eating behaviour by either supporting more informed choice or by changing the market environment'. Furthermore, healthy eating was defined as the adherence to the nutrition recommendations given by the $\mathrm{WHO}^{(19)}$. All the included policies and subsequent projects were selected on the basis that they were financially supported by public funds, whether or not there was also private participation. They had to be part of a larger general policy frame or refer to it. The scope of the present study is exhaustive in the 'type' of interventions, but it is not exhaustive in the number of interventions in all countries.

Data were collected systematically in seventeen out of the twenty-seven EU Member States (see online Supplementary material). The information on the policy interventions was gathered from governmental websites, through general search in databases and peer-reviewed journals, by personal contacts with national public servants and in direct consultation with policy makers. In addition, previous reviews and EU-funded projects were also consulted ${ }^{(4,12,20-24)}$.
Policies were classified into two main branches ${ }^{(25)}$ : (i) policies that support more informed choice, with subcategories of advertising controls, public information campaigns, nutrition education, nutritional labelling and nutritional information on menus; and (ii) policies that intended a change of the market environment, with possible categories of fiscal measures, regulation of meals, nutritionrelated standards (e.g. CODEX Alimentarius), government actions to encourage private sector actions, availability measures for disadvantaged consumers, liability laws and others not specifically targeted to healthy eating but that may influence it. The search was exhaustive in terms of the kind of policy, so that all of them could be represented (S Capacci, M Mazzocchi, B Shankar et al., unpublished results). An exhaustive description of policies, provided as online Supplementary material, is outside the scope of the present paper.

Information about the different interventions was classified into different categories and entered into a database. Categories included the description of the policy/action, its type according to a predetermined list of options, its expected outcomes in terms of health and behaviour, and a potential evaluation approach (details provided as online Supplementary material). Since a larger policy (e.g. Portuguese Platform Against Obesity) may have a number of constituent elements (e.g. information campaign, school meal changes), constituent elements were catalogued separately. Furthermore, policy documents and actions were included only if associated with a healthy eating campaign. In many countries policies remain as such, since their implementation may be postponed or never get executed. Hence, only actions that were related to specific policies were retained to perform the 'evaluation of evaluations' in the present study.

It was then examined whether and to what extent actions were evaluated in terms of their impact on awareness or knowledge, food consumption or intake, and health outcomes (independently of the indicator used), and whether any information was available on implementation costs, budget or, preferably, cost/benefit analysis. Thus interventions were grouped into the following categories: no evaluation; awareness/knowledge evaluation; consumption/intake evaluated; health outcome provided; and cost/benefit calculated.

\section{Results}

\section{Extent and type of evaluations}

Figure 1 shows the distribution of evaluations of impact according to the aforementioned indicators. From the original 121 revised policies, only 107 were retained. The removal criteria for the fourteen policies were: (i) documents containing only guidelines; or (ii) a general framework or 'political intention' but without any further implementation as a consequence. From the 107 selected interventions, 


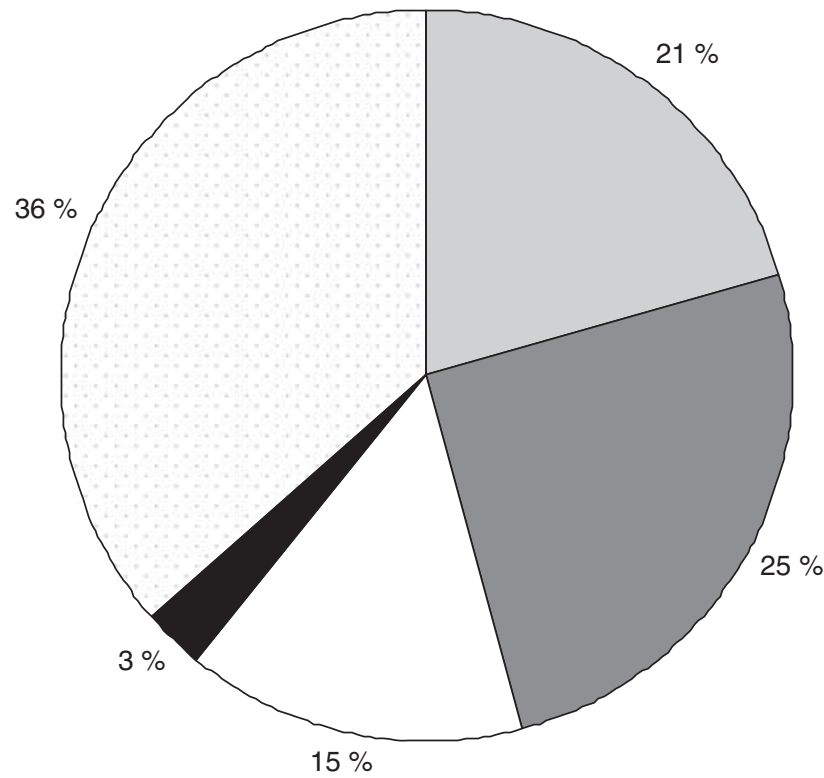

Fig. 1 Availability of policy evaluations in terms of awareness ( $\square$ ), consumption ( $\square$ ), health outcome ( $\square$ ) and costs but not cost/benefit analysis ( $\square ; \square$, no impact assessed)

the larger group (36\%) did not have any evaluation on the basis of the selected indicators. Impact in terms of awareness was evaluated in $21 \%$ of the actions. The measurements of awareness differed methodologically between countries and type of interventions. Some indicators referred to 'remembering slogans of a campaign', others to increased knowledge of what healthy eating is. However, comparability is hindered by the lack of uniform measures and hence of objective assessment.

Seventy-five per cent ( $n$ 80) of the actions that underwent some form of evaluation did not report changes in consumption, or at least did not include specific food consumption as indicators of intervention outcome. As with awareness, comparability of data is hindered by un-harmonized indicators. Some indicators referred to increased fruit and/or vegetable consumption, often in proportions or in quantities; other indicators referred to intake levels of specific nutrients such as iodine, cholesterol, saturated fat, total fat and fibre. Since many EU initiatives and actions targeted at school environments (e.g. breakfasts) are about milk, some actions have been evaluated in terms of milk and dairy products consumption. Snacking and breakfast (consumption or skipping) have also been used as measures of impact on consumption. Finally, lifestyle changes or a combination of lifestyle factors have also been used in some reports about impact on consumption.

Only $15 \%$ of the interventions ( $n$ 16) did an impact assessment on health. The most common way to evaluate the impact on health was to analyse obesity levels before and after the intervention. The French 'Together we fight obesity' (EPODE) and its precursor, the 'Fleurbaix-Laventie Ville Santé' (FLVS) project, the Italian 'Cultura che nutre' and 'Contratto della Merenda' (CDM), the 'Stockholm obesity prevention project' in Sweden and the VIASANO project in Belgium all looked at the prevalence of obesity among their participants. Main indicators for health evaluation have been prevalence levels of overweight and obesity, derived from BMI. In some cases indirect measures such as increased fruit consumption have been reported as an indicator of potential health impact (e.g. Food and Well Being, Wales). The Finnish 'North Karelia program' (NKP) and the Portuguese 'Peso Comunitario' (PPC) also measured blood cholesterol, blood pressure and obesity prevalence as health indicators.

Reporting on the cost of interventions was available for three of the selected evaluations $(2 \cdot 8 \%)$. The main indicators used in this case were the total budgets spent. Only the Finnish NKP stated that population-based prevention through influencing the population's diet and other lifestyle factors is by far the most cost-effective and sustainable way for a reduction in CVD rates and promotion of heart health in the population ${ }^{(26)}$.

None of the following revised categories of actions/ policies in EU countries provided information on the performance indicators: tax/subsidy on foods; subsidies (e.g. vouchers) to disadvantaged consumers targeted at buying healthy foods; advertising controls; nutritional labelling; nutritional information on menus. The only example of a nutrition-related standard is the recent Danish ban on trans fats. However, this action has not been formally evaluated yet.

\section{Evaluations of policies by category}

\section{Public information campaigns}

A policy was classified in this category if it had the aim of improving individual and social knowledge about health issues connected to food habits, making use of mass media (newspapers or television) and was directed to any kind of target population. Most of such campaigns achieved the intended goal of raising awareness and knowledge about healthy eating at population level, as exemplified by the UK's 'five-a-day' ('5D') campaign, which was appraised by The Big Lottery Fund in 2006 and by the EPIC (European Prospective Investigation into Cancer and Nutrition) 'Pilot Evaluation'(27-30). Although the former reported greater levels of improvement in awareness and understanding of the implications of eating fruit and vegetables, only $24 \%$ of surveyed individuals reported an increased fruit and vegetables intake in the previous six weeks. The latter reported that the campaign had a positive effect in people with the lowest intakes, which is relevant for addressing inequalities in health. The Italian 'Eat well, live healthy' campaign, executed between 2003 and 2005 targeting the general population and youth in particular, reported that $37 \cdot 8 \%$ of the participants in their evaluation survey improved their dietary habits as a consequence of the campaign. 


\section{Regulation of school/canteen meals}

This category included any regulation of food supplied at school and work canteens, health standards for canteens and school shops as well as rules on vending machines placed in schools. It also covered the distribution of fruit, milk fountains or other healthy snacks to schoolchildren. The Italian programme 'Eating Together' reported a desirable increase in yoghurt consumption as a snack: $60 \% v .47 \%$ among children at kindergarten and $38 \% v$. $30 \%$ among primary-school children, comparing after $v$. before the campaign. Fruit consumption as a snack in the morning among children at middle school increased ( $6 \cdot 5 \%$ after $v \cdot 3 \cdot 6 \%$ before); fruit consumption in general also increased among adolescents (17\% after $v$. $4 \%$ before), while sweet beverages consumption decreased (3.3\% after $v \cdot 9 \cdot 6 \%$ before). 'Lait scolaire' in France, which was the base for the EU School Milk Programme (SMP) launched in 2008, reported that more than 1700 milk fountains had been installed in school canteens, with the positive outcome of $33 \%$ of teenagers drinking a glass of milk daily at school. In Poland, since 2004, over 366 million 'glasses of milk' have been consumed by pupils under the SMP representing a 178\% annual growth (2007/2008).

An example of workplace action is the Danish 'six-a-day' that consisted of an agreement with companies to provide free fruit to their employees. A behavioural change attributable to this campaign is the $700 \%$ increase in companies providing their employees with free fruit between 2001 and 2003 (a total of 4986 workplaces, 10\% being public) and a resulting daily fruit consumption of $3 \cdot 42$ units on average.

\section{Nutrition education programmes}

'Nutrition education' was defined as any action involving schools or the use of typical educational tools (e.g. training, seminars, lectures) regardless of the age and the target population. The Danish 'All about Diet' programme consists of two web pages providing information to adults and children, a hotline and a rejsebold - a mobile task force helping communities, schools and institutions to improve healthfulness of foods offered. This programme exemplifies the gap between having a policy and its implementation. In $51 \%$ of cases a policy on school food was found, but only $39 \%$ of all participants now provide school food despite an overall satisfaction with the programme.

The Portuguese PPC is targeted to the general adult population, and comprises training sessions. The evaluation reported reductions in total energy intake $(-6 \cdot 3 \%)$, cholesterol $(-9 \cdot 2 \%)$, total fat $(-12 \cdot 2 \%)$ and saturated fat $(-15 \cdot 6 \%)$ between baseline and follow-up. The programme also claimed a desirable increase of $7.6 \%$ in fibre consumption. The private-public partnership 'Programa Educativo apetece-me' aimed at providing information about food, nutrition, health and well-being in school. It had an impact on food habits as reported after quantitative and qualitative evaluations. However, no objectively verifiable data were available for either of the evaluations. The regional programme PASSE consists of a series of tools for the promotion of healthy eating that were developed for targeted age groups, teachers and health practitioners. This programme has collected impact assessment data, which are not yet publicly available.

\section{Advertisement regulations}

This class covered all regulations regarding advertising of unhealthy foods to different population segments, particularly children. In 2007, the UK communications regulator, OFCOM (formerly the Independent Television Commission), introduced a series of rules prohibiting the advertisement of foods high in fat, salt and sugar during children's television programmes. The intervention was evaluated mostly in terms of children's exposure to advertising messages on television, concluding that children aged 4-9 years saw 39\% less advertising of unhealthy food, while children aged 10-15 years saw 28\% less advertising compared with the same period before the ban's implementation. Similar bans were applied in Sweden and Denmark, but these have not been evaluated yet. In France, the food advertising 'mandatory health messages' campaign claimed its success being due to simple and straightforward messages and to the use of television as the means for broadcasting them.

\section{Combination of policies}

This category included cases in which more than one type of policy was implemented. A classic example is the Finnish NKP that combined strong public information campaigns, nutrition education, stakeholder involvement and community participation. NKP further emphasised that populationbased prevention through influencing the population's diet and other lifestyle factors seems the most cost-effective and sustainable way for reducing CVD rates and promoting heart health in the population ${ }^{(26)}$. Another example is the French FLVS that combined nutrition education, information campaigns, regulation of school meals, physical activity and private-public partnerships. During the first period of the FLVS study (from 1992 to 2000) the prevalence of childhood overweight first tended to increase. During the second period (from 2000 to 2004), this level decreased in FLVS whereas it increased in the control towns ${ }^{(31,32)}$. The subsequent French programme EPODE has registered children's heights and weights systematically, and found an overall decrease in the prevalence of obesity of almost 2\% during the period 2005-2007. The Portuguese Platform Against Obesity's claimed success in bringing behavioural changes (reduced fat intake or improved food habits) could not be supported by publicly available and reliable evaluation indicators.

\section{Discussion}

The Global Database on National Nutrition Policies and Programmes was established in 1995, to monitor and 
evaluate the progress in implementing the World Declaration and Plan of Action for Nutrition. All documents call for monitoring and evaluating the impacts of the different programmes but evaluations are not performed yet. Although several potential useful indicators exist at the WHO's European Health For All database, like protein and energy consumption, particular attention should be given to other markers of healthy eating and nutritional status of the population. It is plausible that many countries and policy actions may have performed evaluations of their performance; nevertheless, such information is rarely available in English, online or accessible to the general public, as exemplified by PASSE in Portugal or Tutti-Frutti in Belgium.

Regarding public information campaigns, there is evidence from consumer surveys (on food) and selfcompleted questionnaires (on health-related attitudes and outcomes) that more people now know and understand what is meant by a healthy diet, even if this does not always translate into consistent practice (e.g. Food and Well Being, Wales). What remains a challenge is the impact assessment of actions such as the '5D' campaign since ecological observations based on aggregated data suggest that observed changes in intake are not nutritionally relevant ${ }^{(33)}$. In Poland a milk-focused campaign (Mlekosław) reported that advertisements were remembered by $27 \%$ of mothers and $44 \%$ of children; however, it did not influence significantly actual consumption habits $^{(34)}$. Contrary to previous reports on Canadian interventions ${ }^{(35)}$, such results indicate that awareness and knowledge do not translate into behaviour, and exemplify the gap between attitudes and behaviour ${ }^{(36)}$.

Conflicting findings were observed as a result of the present study. On the one hand, for example, the NKP suggests that "change in actual behaviour is possible (26) resulting in improved health and longer life expectancy at population level, and FLVS ${ }^{(31)}$ claims success in overweight reduction among children ${ }^{(31,32)}$. On the other hand, interventions like the UK's '5D' or the Italian 'FruitSnack campaign' showed no substantial increase in actual fruit and vegetable consumption, just like other modest results of population-level CHD prevention actions ${ }^{(37)}$. Heterogeneity in terms of study design, theoretical foundations and target populations hinder comparability and generalisation of these findings, similar to what was reported for weight gain prevention(38). Probably different settings and the length of the interventions may be potential confounding factors. Positive synergistic effects of integrating vertical and horizontal interventions of weight loss and weight management may enhance their sustainability, and increase effectiveness of prevention and reduction efforts ${ }^{(39)}$. Such contradictions would be avoided if an agreed protocol and measurement technique/unit were to be applied for evaluation.

Regarding interventions regulating school/canteen meals, some desirable trends were observed, particularly higher fruit, vegetable or milk consumption and less breakfast skipping. This is consistent with reports about policy interventions that make healthy dietary and physical activity choices easier, which are likely to achieve the greatest benefits in combating childhood obesity for example $^{(40,41)}$. Skipping breakfast ${ }^{(42,43)}$ and snacking ${ }^{(44)}$ could be mentioned among food intake patterns related to obesity and overweight. Breakfast skipping is associated with lower cognitive and academic performance ${ }^{(45-47)}$. Eating between meals or snacking has become the source of at least $25 \%$ of total energy intake in different EU settings and it provides more than the recommended quantities of added sugars and saturated fatty acids ${ }^{(44)}$. Hence, strategies specifically directed to the promotion of healthy breakfast and snacking habits are more likely to achieve success ${ }^{(48,49)}$ if they take into account socio-economic, sociodemographic and attitudinal differences ${ }^{(36,50)}$.

Nutrition education in schools can be successful in promoting awareness and generating healthy habits such as snacking with fruit, as the Italian CDM reported. Such a programme would not have been possible without parents' involvement and their awareness of the importance of nutrition education $^{(20,51)}$. Furthermore, this exemplifies the need for strategic alliances between concerned actors and stakeholders in carrying out the task of promoting healthy eating which would yield better academic performance and long-term health ${ }^{(35,48-50)}$. Yet evidence remains contradictory; e.g. in US schools, participation in School Breakfast Programs has been reported as beneficial in the prevention of obesity, while participation in the National School Lunch Program seems to exacerbate the obesity levels among youths ${ }^{(52)}$. Other multi-sector projects such as PASSE in Portugal have implemented evaluation procedures that will provide information on the effectiveness of the intervention. However such information is not yet publicly available.

\section{Conclusions}

The present study has shown that a large share of healthy eating policies has not been evaluated yet or their evaluation results are not public. The categories that are more likely to have a better or further-reaching evaluation are: (i) public information campaigns; (ii) regulation of meals at school/canteens; and (iii) nutrition education programmes. In general little or no evaluations have been carried out in terms of (or measured as) behavioural changes and cost/benefit.

The overall results of the study highlight issues to be considered in future policy formulation and action's evaluation. First, public information campaigns seem to be successful in increasing awareness, in creating an intention to engage in desired behaviours, but they fail to achieve actual behavioural change (reported as e.g. healthy eating). Second, there are a number of examples of potentially successful interventions classified as nutrition 
education in schools, particularly when a multi-sector and bottom-up approach is applied. Addressing healthy eating from a multidisciplinary and comprehensive perspective and the use of a range of actions can give better results ${ }^{(20)}$. It seems that the general population is more likely to engage in any intervention where it feels part of it ${ }^{(53,54)}$. Third, regulating school/canteen meals is more likely to help students not to skip breakfasts and improve their healthy eating choices through improvement in terms of availability, but in the case of school meals regulations, they need to be comprehensive and also involve the parents ${ }^{(15,55,56)}$.

Because combinations of policies, such as with $\mathrm{NKP}^{(26)}$ and FLVS ${ }^{(31)}$, have been better evaluated, either because of their long-standing life or their design, the evidence suggests that any policy aimed at healthy eating may be successful if there is a component of multi-stakeholder involvement and if the approach includes the synergy of different types of policy instruments ${ }^{(57)}$. Furthermore, the present study emphasises the need for harmonised and verifiable indicators for measuring success and comparing between countries, and advocates for better informed (evidence based) policy choices. Proper evaluations should be included in any public-funded action, particularly when health outcomes are expected. Reasonable health outcomes such as reduced overweight levels or increased physical activity do not appear from one day to the other; such changes need time and it is a hard process. It is clear that changes at population level require a reasonable time frame to be measurable, e.g. weight loss or changes in nutritional status ${ }^{(32)}$. Planning strategically ahead of time and applying pertinent indicators will prevent waste of public resources in interventions that may not have any significant effect ${ }^{(17,41,58,59)}$. The cost/ benefit analyses performed by some actions suggest that prevention is indeed cheaper than treatment of obesity.

EU policies should provide a set of indicators that may be regularly collected in all countries. Such indicators should be able at least to measure the impact of policies on food and nutrient intakes. Since impact on health is mostly measured using nutritional status based on BMI, anthropometric measures should be included in regular surveys, although performing those measurements is time consuming and requires expertise. BMI-based nutritional status categories from measured heights and weights are, however, the most reliable epidemiological indicator for population studies ${ }^{(60,61)}$.

Distinction should be made between the evaluation of impact on intentions, attitudes, knowledge and behaviour. Measured knowledge of specific messages does not imply adopting a desirable behaviour (healthy eating, increased physical activity, etc.), since other drivers of behaviour may play a role, particularly when e.g. individuals have to choose between different food items ${ }^{(50,62,63)}$. Since most 'healthy eating' policies advocate the increased consumption of foods of plant origin, limited consumption of meats and energy-dense foods, and also decreased consumption of processed meats and sugary drinks, our suggestion would be to include key indicators of food consumption or availability ${ }^{(64)}$ using harmonised data collection schemes in Europe for any proper evaluation of future policies. Unless such harmonised data are systematically collected and analysed, evaluations of policies in terms of economic cost/benefit at population level will not be achievable.

\section{Acknowledgements}

The work was supported financially by the European Community under the Seventh Framework Programme for Cooperation, Theme Food, Agriculture and Fisheries, and Biotechnology, Contract 226713. Preliminary findings from this manuscript were presented orally at the Second Congress of Public Health Nutrition in Porto, Portugal, and won the Research Excellence Award to the free paper competition \# 1. The authors declare that they have no conflicts of interest. F.J.A.P.-C., J.A.-W., S.C., J.B.-M., A.K.-K., B.P. and A.T. were involved in data collection and analysis. F.J.A.P.-C. and J.A.-W. drafted the first version of the manuscript. W.V., W.B.T., B.S., M.M., B.N., T.B.-L., A.S., A.T. and J.W. contributed critically to the content of the article. J.W. revised the language. W.B.T. was the Project Coordinator.

\section{References}

1. Bundred P, Kitchiner D \& Buchan I (2001) Prevalence of overweight and obese children between 1989 and 1998: population based series of cross sectional studies. BMJ 322, 326-328.

2. Romon M, Duhamel A, Collinet N et al. (2005) Influence of social class on time trends in BMI distribution in 5-year-old French children from 1989 to 1999. Int J Obes (Lond) 29, 54-59.

3. World Health Organization (2007) The Challenge of Obesity in the WHO European Region and the Strategies for Response. Copenhagen: WHO Regional Office for Europe.

4. Lobstein T \& Millstone E (2007) Context for the PorGrow study: Europe's obesity crisis. Obes Rev 8, Suppl. 2, 7-16.

5. Elmadfa I (2009) European Nutrition and Health Report 2009 executive summary introduction. Ann Nutr Metab 55, $3-40$.

6. Perez-Cueto FJA, Verbeke W, de Barcellos MD et al. (2010) Food-related lifestyles and their association to obesity in five European countries. Appetite 54, 156-162.

7. The Strategy Unit, Cabinet Office (2008) Food Matters. Towards a Strategy for the 21st Century. London: Cabinet Office.

8. Yu AP, Wu EQ, Birnbaum HG et al. (2007) Short-term economic impact of body weight change among patients with type 2 diabetes treated with antidiabetic agents: analysis using claims, laboratory, and medical record data. Curr Med Res Opin 23, 2157-2169.

9. Goldman D, Michaud PC, Lakdawalla D et al. (2010) The fiscal consequences of trends in population health. Nat Tax J 63, 307-330.

10. World Health Organization (2003) Comparative Analysis of Food and Nutrition Policies in WHO European Member States. Copenhagen: WHO Regional Office for Europe. 
11. World Health Organization (2008) WHO European Action Plan for Food and Nutrition Policy 2007-2012. Copenhagen: WHO Regional Office for Europe.

12. Lachat C, Van Camp J, De Henauw S et al. (2005) A concise overview of national nutrition action plans in the European Union Member States. Public Health Nutr 8, 266-274.

13. Luttikhuis HO, Baur L, Jansen $\mathrm{H}$ et al. (2009) Interventions for treating obesity in children. Cochrane Database Syst Rev issue 1, CD001872.

14. Sharma M (2007) Behavioural interventions for preventing and treating obesity in adults. Obes Rev 8, 441-449.

15. Sharma M (2006) School-based interventions for childhood and adolescent obesity. Obes Rev 7, 261-269.

16. Bluford DAA, Sherry B \& Scanlon KS (2007) Interventions to prevent or treat obesity in preschool children: a review of evaluated programs. Obesity (Silver Spring) 15, 1356-1372

17. Burris S, Wagenaar AC, Swanson J et al. (2010) Making the case for laws that improve health: a framework for public health law research. Milbank $O \mathbf{8 8}, 169-210$.

18. Traill WB, Perez-Cueto FJA, Shankar B et al. (2010) EATWELL Project: approaching European healthy eating policies from a multi-disciplinary perspective. Nutr Hosp 25, 867-868.

19. World Health Organization (2004) Global Strategy on Diet, Physical Activity and Health. Geneva: WHO.

20. De Bourdeaudhuij I, Van Cauwenberghe E, Spittaels H et al. (2011) School-based interventions promoting both physical activity and healthy eating in Europe: a systematic review within the HOPE project. Obes Rev 12, 205-216.

21. Kristjansdottir AG, De Bourdeaudhuij I, Klepp KI et al. (2009) Children's and parents' perceptions of the determinants of children's fruit and vegetable intake in a lowintake population. Public Health Nutr 12, 1224-1233.

22. Finkelstein E, Fiebelkorn IC \& Wang GJ (2005) The costs of obesity among full-time employees. Am J Health Promot 20, 45-51.

23. Story M, Kaphingst KM, Robinson-O'Brien R et al. (2008) Creating healthy food and eating environments: policy and environmental approaches. Annu Rev Public Health 29, 253-272.

24. Kumanyika SK, Obarzanek E, Stettler N et al. (2008) Population-based prevention of obesity: the need for comprehensive promotion of healthful eating, physical activity, and energy balance: a scientific statement from American Heart Association Council on Epidemiology and Prevention, Interdisciplinary Committee for Prevention (formerly the expert panel on population and prevention science). Circulation 118, 428-464.

25. Mazzocchi M \& Traill WB (2005) Nutrition, health and economic policies in Europe. Food Econ - Acta Agric Scand, Section C 2, 138-149.

26. Puska P (2009) Fat and heart disease: yes we can make a change - the case of North Karelia (Finland). Ann Nutr Metab 54, 33-38.

27. Ashfield-Watt PAL, Welch AA, Day NE et al. (2004) Is 'five-aday' an effective way of increasing fruit and vegetable intakes? Public Health Nutr 7, 257-261.

28. Ashfield-Watt PAL (2006) Fruits and vegetables, 5+ a day: are we getting the message across? Asia Pacific J Clin Nutr 15, 245-252.

29. Ashfield-Watt PAL, Welch AA, Godward S et al. (2007) Effect of a pilot community intervention on fruit and vegetable intakes: use of FACET (Five-a-day Community Evaluation Tool). Public Health Nutr 10, 671-680.

30. Myint PK, Welch AA, Bingham SA et al. (2007) Fruit and vegetable consumption and self-reported functional health in men and women in the European Prospective Investigation into Cancer-Norfolk (EPIC-Norfolk): a populationbased cross-sectional study. Public Health Nutr 10, 34-41.
31. Borys JM, Romon M \& Raffin S (2007) Long term outcomes of a successful childhood obesity prevention program in France: FLVS (Fleurbaix Laventie Ville Sante). Int J Obes (Lond) 31, Suppl. 1S, S200 (abstract).

32. Romon M, Lommez A, Tafflet M et al. (2009) Downward trends in the prevalence of childhood overweight in the setting of 12-year school- and community-based programmes. Public Health Nutr 12, 1735-1742.

33. Capacci S \& Mazzocchi M (2011) Five-a-day, a price to pay: an evaluation of the UK program impact accounting for market forces. J Health Econ 30, 87-98.

34. Świątkowska M (2009) Advertising of product categories as a tool to support the development of dairy sector in Poland. Roczniki Naukowe Stowarzyszenia Ekonomistów Rolnictwa i Agrobiznesu 11, 366-371.

35. Ransome K, Rusk J, Yurkiw MA et al. (1998) A school milk promotion program increases milk consumption and improves the calcium and vitamin D intakes of elementary school students. Can J Diet Pract Res 59, 190-198.

36. Kaiser FG \& Schultz PW (2009) The attitude-behavior relationship: a test of three models of the moderating role of behavioral difficulty. J Appl Soc Psychol 39, 186-207.

37. Papadakis S \& Moroz I (2008) Population-level interventions for coronary heart disease prevention: what have we learned since the North Karelia project? Current Opin Cardiol 23, 452-461.

38. Lemmens V, Oenema A, Klepp KI et al. (2008) A systematic review of the evidence regarding efficacy of obesity prevention interventions among adults. Obes Rev 9, 446-455.

39. MacLean LM, Clinton K, Edwards N et al. (2010) Unpacking vertical and horizontal integration: childhood overweight/ obesity programs and planning, a Canadian perspective. Implement Sci $\mathbf{5}, 36$.

40. Sallis JF \& Glanz K (2009) Physical activity and food environments: solutions to the obesity epidemic. Milbank $Q$ 87, 123-154.

41. Frieden TR, Dietz W \& Collins J (2010) Reducing childhood obesity through policy change: acting now to prevent obesity. Health Aff (Millwood) 29, 357-363.

42. Herrero-Lozano R \& Fillat-Ballesteros JC (2006) Estudio sobre el desayuno y el rendimiento escolar en un grupo de adolescentes. Nutr Hosp 21, 346-352.

43. Morales IF, Vilas MVA, Vega CJM et al. (2008) Relation between the breakfast quality and the academic performance in adolescents of Guadalajara (Castilla-La Mancha). Nutr Hosp 23, 383-387.

44. Macdiarmid J, Loe J, Craig LCA et al. (2009) Meal and snacking patterns of school-aged children in Scotland. Eur J Clin Nutr 63, 1297-1304

45. Pollitt E \& Mathews R (1998) Breakfast and cognition: an integrative summary. Am J Clin Nutr 67, issue 4, 804S-813S.

46. Musaiger AO, bin Zaal AA \& D'Souza R (2009) Dietary habits associated with obesity among adolescents in Dubai, United Arab Emirates. Nutr Hosp 24, 437-444.

47. Fernandez AC, Weigand CM, Pomar MDB et al. (2011) Changes on dietary habits of the late-breakfast in a school population. Nutr Hosp 26, 560-565.

48. Rahmani K, Djazayery A, Habibi MI et al. (2011) Effects of daily milk supplementation on improving the physical and mental function as well as school performance among children: results from a school feeding program. J Res Med Sci 16, 469-476.

49. Naylor PJ \& McKay HA (2009) Prevention in the first place: schools a setting for action on physical inactivity. BrJ Sports Med 43, 10-13.

50. Salamon P, Pfau C, Grillenberger M et al. (2010) School milk demand: design and first results of the German federal 
research project 'Focus on school milk'. Landbauforschung 60, 1-10.

51. Harker D, Sharma B, Harker M et al. (2010) Leaving home: food choice behavior of young German adults. J Bus Res 63, 111-115.

52. Millimet DL, Tchernis R \& Husain M (2010) School nutrition programs and the incidence of childhood obesity. J Hum Resour 45, 640-654.

53. Sallis JE, Cervero RB, Ascher W et al. (2006) An ecological approach to creating active living communities. Annu Rev Public Health 27, 297-322.

54. Ventura AK \& Birch LL (2008) Does parenting affect children's eating and weight status? Int J Behav Nutr Phys Act 5, 15.

55. Brown T \& Summerbell C (2009) Systematic review of school-based interventions that focus on changing dietary intake and physical activity levels to prevent childhood obesity: an update to the obesity guidance produced by the National Institute for Health and Clinical Excellence. Obes Rev 10, 110-141.

56. Campbell KJ \& Hesketh KD (2007) Strategies which aim to positively impact on weight, physical activity, diet and sedentary behaviours in children from zero to five years. A systematic review of the literature. Obes Rev $\mathbf{8}$, $327-338$.
57. Mohebati L, Lobstein T, Millstone E et al. (2007) Policy options for responding to the growing challenge from obesity in the United Kingdom. Obes Rev 8, 109-115.

58. Kim D \& Kawachi I (2006) Food taxation and pricing strategies to 'thin out' the obesity epidemic. Am J Prev Med 30, 430-437.

59. Murimi MW \& Harpel T (2010) Practicing preventive health: the underlying culture among low-income rural populations. J Rural Health 26, 273-282.

60. Rothman KJ (2008) BMI-related errors in the measurement of obesity. Int J Obes (Lond) 32, Suppl. 3, S56-S59.

61. Perez-Cueto FJA \& Verbeke W (2009) Reliability and validity of self-reported weight and height in Belgium. Nutr Hosp 24, 366-367.

62. Resano H, Verbeke W, de Barcellos MD et al. (2010) Obesity and overall satisfaction with pork meat and derived pork-based products. Nutr Hosp 25, 123-124.

63. Sharma B, Harker M, Harker D et al. (2010) Youth transition to university in Germany and Australia: an empirical investigation of healthy eating behaviour. J Youth Stud 13, 353-367.

64. Lagiou P, Trichopoulou A \& Contributors D (2001) The DAFNE initiative: the methodology for assessing dietary patterns across Europe using household budget survey data. Public Health Nutr 4, 1135-1141. 